\title{
Antinociceptive effect of continuous intrathecal administration of endomorphin-1
}

\author{
Emese Csullog ${ }^{\mathrm{a}, \mathrm{b}}$, Gabriella Joo ${ }^{\mathrm{a}}$, Geza Toth ${ }^{\mathrm{c}}$, Ildiko Dobos ${ }^{\mathrm{a}}$, \\ György Benedek ${ }^{\mathrm{a}}$, Gyöngyi Horvath ${ }^{\mathrm{a}, \mathrm{d}, *}$ \\ ${ }^{\mathrm{a}}$ Department of Physiology, Faculty of Medicine, University of Szeged, P.O. Box 427, H-6701 Szeged, Hungary
${ }^{\mathrm{b}}$ Department of Anesthesiology and Intensive Care, Faculty of Medicine, University of Szeged, Szeged, Hungary
${ }^{\mathrm{c}}$ Isotope Laboratory of Biological Research Center of the Hungarian Academy of Sciences, Szeged, Hungary
${ }^{\mathrm{d}}$ Department of Physical Therapy, Faculty of Health Science, University of Szeged, Szeged, Hungary
}

Received 2 January 2001; received in revised form 12 April 2001; accepted 3 May 2001

\begin{abstract}
Endomorphin-1 is a novel endogenous opioid peptide with high affinity and selectivity for the $\mu$-opioid receptor. Earlier results have shown that it causes antinociception in different pain tests, but its effect is short-lasting. The purpose of the present study was to investigate the antinociceptive potency of continuously administered endomorphin- 1 on carrageenan-induced thermal hyperalgesia by means of a paw withdrawal test in awake rats. The possible interaction between endomorphin- 1 and the C-terminal octapeptide of the novel endogenous peptide nocistatin (bPNP-3-8P) was examined in the same experimental set-up. Continuous administration of endomorphin-1 (0.1, $0.3,1$ or $2 \mu \mathrm{g} / \mathrm{min}$ for $60 \mathrm{~min}$ ) did not influence the paw withdrawal latencies of the normal paws. On the inflamed side, endomorphin-1 dosedependently decreased the thermal hyperalgesia during continuous administration. The cessation of administration resulted in a gradual decrease in the antinociceptive effect of endomorphin-1. bPNP-3-8P (0.003-30 $\mu \mathrm{g}$, administered cumulatively) significantly decreased the heat hyperalgesia at higher doses $(3$ and $30 \mu \mathrm{g})$. Continuous administration of bPNP-3-8P $(0.03,0.1 \mathrm{and} 1 \mu \mathrm{g} / \mathrm{min}) \mathrm{did}$ not potentiate the antinociceptive effect of endomorphin-1; instead, it even shortened the duration of its effect. The results demonstrate that continuous administration of endomorphin-1 is an effective method of inhibiting thermal hyperalgesia in rats. Furthermore, the fragment bPNP-3-8P itself has low antinociceptive potency and does not potentiate the antinociceptive effect of endomorphin-1 under these circumstances. (C) 2001 International Association for the Study of Pain. Published by Elsevier Science B.V. All rights reserved.
\end{abstract}

Keywords: Continuous infusion; Endomorphin-1; Interaction; Nocistatin; Pain; Spinal

\section{Introduction}

Chronic pain caused by inflammation is known to be clinically associated with hyperalgesia. Carrageenaninduced inflammatory hyperalgesia has been widely used as an animal model to study the mechanism of nociception and to screen for anti-inflammatory drugs. It has been shown that peripheral inflammatory hyperalgesia is due, at least in part, to the enhancement of synaptic transmission mediated by substance $\mathrm{P}$ and excitatory amino acids in the spinal dorsal horn (Ren et al., 1992; Traub, 1996). The dorsal horn constitutes the first relay station for incoming somatosensory information, and many substances (including

\footnotetext{
* Corresponding author. Department of Physiology, Faculty of Medicine, University of Szeged, P.O. Box 427, H-6701 Szeged, Hungary. Tel.: +3662-544-971; fax: +36-62-545-842.

E-mail address: horvath@phys.szote.u-szeged.hu (G. Horvath).
}

peptides) are involved in the modulation of pain information at this level. Two tetrapeptides, endomorphin-1 and endomorphin-2 (Tyr-Pro-Trp-Phe- $\mathrm{NH}_{2}$ and Tyr-Pro-Phe-Phe$\mathrm{NH}_{2}$, respectively), have been identified as endogenous ligands of the $\mu$-opioid receptors (Zadina et al., 1997). They activate these receptors with high affinity and selectivity (Zadina et al., 1997). Since morphine and other opiates produce their analgesic effects primarily through the $\mu$-opioid receptor, endomorphins may represent a class of endogenous opioids that have therapeutic potential. The presence of a dense aggregation of endomorphin-like immunoreactive elements in the superficial dorsal horns of the medulla and spinal cord indicates that endomorphins are likely to modulate nociceptive transmission (Martin-Schild et al., 1997; Wu et al., 1999). There is behavioural evidence that these peptides produce potent analgesia in rodents under different pain conditions such as acute, inflammatory and neuropathic pain models (Horvath, 2000). The data 
concerning the duration of their action are somewhat controversial. Some studies found long-lasting antinociception (Zadina et al., 1997; Wang et al., 1999a,b), while others reported a short-lasting effect of endomorphin-1 which had disappeared completely 15-30 min following administration (Stone et al., 1997; Horvath et al., 1999; Mizoguchi et al., 1999; Bhatia et al., 2000; Grass et al., 2000; Soignier et al., 2000). This short course of action suggests a rapid degradation in the spinal cord, although the results in this respect are controversial (Shane et al., 1999; Péter et al., 1999; Sugimoto-Watanabe et al., 1999). The short-lasting effect of endomorphins might inhibit their introduction in human pain therapy. One possibility whereby this phenomenon might be overcome is the continuous administration of the drug. The primary goal of the present study was to assess the antinociceptive effect of endomorphin-1 during continuous intrathecal administration.

Another recently discovered endogenous peptide that has been implicated in the modulation of pain transmission is nocistatin (a heptadecapeptide), produced by the proteolytic cleavage of prepronociceptin. Prepronociceptin is also the parent substance of nociceptin, the endogenous ligand for the opioid-receptor-like receptor (Okuda-Ashitaka et al., 1998). The name nocistatin originates from observations that it prevents or reverses the activity of nociceptin in several (but not all) in vivo and in vitro assays (OkudaAshitaka et al., 1998; Nicol et al., 1998; Hiramatsu and Inoue, 1999; Häbler et al., 1999; Connor et al., 1999). Nocistatin is widely present in the brain and the spinal cord (Okuda-Ashitaka and Ito, 2000), and it presumably acts as a neuromodulator in spinal pain processing, since it blocks the hyperalgesia and allodynia induced by nociceptin or prostaglandin- $\mathrm{E}_{2}$ (Okuda-Ashitaka et al., 1998). Okuda-Ashitaka et al. (1998) have shown that the C-terminal octapeptide of nocistatin (Glu-Ile-Glu-Gln-Lys-GlnLeu-Gln = bPNP-3-8P) has similar biological activity to that of the heptadecapeptide in inhibiting nociceptininduced allodynia, and this fragment is crucial for the activity. Since the only two studies of the effect of this fragment furnished opposite results (Okuda-Ashitaka et al., 1998; Xu et al., 1999), the second goal of the present study was to determine the antinociceptive potency of bPNP-3-8P on carrageenan-induced hyperalgesia.

There are also few results which suggest an interaction between nociceptin and endomorphins (Wang et al., 1999a,b). Since nocistatin antagonizes the effect of nociceptin, and the above-mentioned findings strongly suggest that both nocistatin and the endomorphins are involved in spinal pain transmission, there is a possibility for an interaction between the endogenous opioid, endomorphin-1 and nocistatin. Few data are available on the possible interaction between the opioid system and nocistatin until now (Zhao et al., 1999; Nakano et al., 2000), and none on the interaction of endomorphin-1 with bPNP-3-8P. The third goal of our study was therefore to analyze the possible interaction of continuously administered endomorphin-1 and bPNP-3-8P on an inflammatory pain model at the spinal level.

\section{Methods}

\subsection{Animals}

Animal surgery and testing were approved by the institutional animal care committee of the University of Szeged Faculty of Medicine. Male Wistar rats $(n=131)$ weighing $302.6 \pm 2.71 \mathrm{~g}$ were used in the experiments. The rats were anaesthetized with ketamine and xylazine $(72$ and $8 \mathrm{mg} / \mathrm{kg}$ intraperitoneally, respectively). An intrathecal catheter (PE10 tubing) was inserted via the cisterna magna and passed $8.5 \mathrm{~cm}$ caudally. The skin incision was closed, leaving $2 \mathrm{~cm}$ of the catheter free above the skull. The rats were allowed to recover for at least 4 days before testing. Animals exhibiting any postoperative neurological impairment were excluded from the study. All experiments were carried out during the same period of the day in order to exclude diurnal variations in pharmacologic effects. At the end of the study, the animals were killed with an overdose of pentobarbital, and methylene blue was injected intrathecally to evaluate the position of the catheter. The animals were randomly assigned to treatment groups ( $n=5-11$ per group), and the observer was blind to the treatment administered.

\subsection{Drugs}

The following drugs were administered: ketamine hydrochloride (Ketalar; Parke-Davis, Vienna, Austria), xylazine (Rompun TS; Bayer AG, Leverkusen, Germany), and carrageenan lambda (Sigma-Aldrich Kft., Budapest, Hungary). Endomorphin-1 and bPNP-3-8P were synthesized by a solid-state method and purified by means of HPLC in the Isotope Laboratory of the Biological Research Center of the Hungarian Academy of Sciences. The peptide solutions in sterile physiological saline were freshly prepared on the day of the experiment.

In the series involving bPNP-3-8P administration alone, the drug or saline was injected intrathecally at a volume of $5 \mu \mathrm{l}$ over $30 \mathrm{~s}$, followed by a $10 \mu \mathrm{l}$ flush of physiological saline. Since only a few data are available about bPNP-3-8P - for the sake of getting the effective dose - we used a very wide dose intervallum and in this case the drug was applied cumulatively $(0.003-30 \mu \mathrm{g})$ every $30 \mathrm{~min}$.

In the further series when the endomorphin-1 and bPNP3-8P were administered continuously, the animals were connected to a microinjection syringe pump (2Biological Instruments) via calibrated tubing. Drugs were injected at a volume of $60 \mu \mathrm{l}$, followed by $10 \mu \mathrm{l}$ of saline to wash the catheter. Drugs were injected at a flow rate of $1 \mu \mathrm{l} / \mathrm{min}$. The control group received saline intrathecally. 


\subsection{Inflammatory pain test (paw withdrawal test)}

The rats were placed on a glass surface in a plastic chamber and were allowed to acclimatize to their environment for 15-30 min before testing, and the baseline hindpaw withdrawal latencies (pre-carrageenan baseline values at $-180 \mathrm{~min}$ ) were obtained. The heat stimulus was directed onto the plantar surface of each hindpaw. The cut-off time was set at $20 \mathrm{~s}$ to avoid tissue damage. A detailed description of this method has been published elsewhere (Hargreaves et al., 1988). Unilateral inflammation was induced by intraplantar injection of $1.5 \mathrm{mg}$ carrageenan in $0.1 \mathrm{ml}$ physiological saline into one of the hindpaws. The paw withdrawal latencies were obtained again $3 \mathrm{~h}$ after carrageenan injection (post-carrageenan baseline values at $0 \mathrm{~min}$ ) and at $10 \mathrm{~min}$ intervals afterwards for $130 \mathrm{~min}$.

\subsection{Experimental paradigm}

\subsubsection{Dose-response curves for single drugs}

The first series of experiments was performed to determine the dose-response effect of endomorphin-1 $(0.1,0.3,1$ and $2 \mu \mathrm{g} / \mathrm{min}$, continuous administration, total dose: 6,18 , 60 and $120 \mu \mathrm{g}$ during $60 \mathrm{~min})$ and bPNP-3-8P (0.003-0.03$0.3-3-30 \mu \mathrm{g} / 5 \mu \mathrm{l}$, cumulative administration).

\subsubsection{Drug interaction}

The second series of experiments was performed with different doses of endomorphin-1 and bPNP-3-8P in order to determine the possible antinociceptive interaction of the two drugs. In this series, both bPNP-3-8P (0.03, 0.1 and $1 \mu \mathrm{g} / \mathrm{min})$ and endomorphin-1 $(0.1,0.3,1$ and $2 \mu \mathrm{g} / \mathrm{min})$ were administered continuously and simultaneously.

\subsection{Data analysis}

Data are presented as means \pm SEM. Data sets were examined by analyses of variance (ANOVA) with repeated measures. The area under the curve (AUC) values were obtained by calculating the area during drug administration (10-60 min) and after drug administration (100-130 min). These data sets were examined by one-way ANOVA. The significance of differences between experimental and control values was calculated by using the LSD post hoc test. A $P$-value of less than 0.05 was considered significant.

\section{Results}

Before the microinfusion, the mean paw withdrawal latency was $10.05 \pm 0.09 \mathrm{~s}$ and did not differ significantly between the groups. The intraplantar injection of carrageenan reduced the nociceptive threshold of the treated paw significantly to $3.07 \pm 0.12 \mathrm{~s}(P<0.05)$, indicating hyperalgesia. This hyperalgesia persisted throughout the investigation in the saline-treated group (Fig. 1A).

\subsection{Single drug administration}

\subsubsection{Endomorphin-1}

None of the administered doses of endomorphin-1 changed the paw withdrawal latencies on the non-inflamed side significantly, although the highest dose tended to increase it (Fig. 1B,E). The lowest dose of endomorphin-1 did not cause a significant increase in the paw withdrawal latencies on the inflamed side as compared to the post-carrageenan values. The higher doses caused significant increases in the paw withdrawal latencies at several time points, although significant differences from the baseline values were observed at almost all time points, suggesting that the hyperalgesia was merely decreased, but not relieved. Analysis of the AUC data revealed that the hyperalgesia decreased dose-dependently in the 10-60 min interval, although $2 \mu \mathrm{g} /$ min was less effective than $1 \mu \mathrm{g} / \mathrm{min}$, suggesting the development of a ceiling effect (Fig. 2E). The cessation of administration resulted in a gradual decrease in the paw withdrawal latencies (Fig. 1B,E), though analysis of the AUC values revealed significant differences between the control and the 0.3 or $1 \mu \mathrm{g} / \mathrm{min}$ endomorphin-1-treated group in the period 100-130 min (Fig. 2F).

\subsection{2. $b P N P-3-8 P$}

bPNP-3-8P at higher doses $(0.3-30 \mu \mathrm{g})$ significantly increased the paw withdrawal latencies for the inflamed hindpaws as compared to the post-carrageenan values (Fig. 1F). There were no signs of motor impairment.

\subsection{Drug interaction}

None of the doses of bPNP-3-8P influenced significantly the antinociceptive effect of endomorphin-1 during the infusion (Fig. 2). After the cessation of administration, the AUC values showed that bPNP-3-8P shortened the antinociceptive effect of $1 \mu \mathrm{g} / \mathrm{min}$ endomorphin-1 (Fig. 2F). No treatment caused any motor impairment.

\section{Discussion}

The most important finding from our study is the potent antihyperalgesic effect of endomorphin-1 during continuous administration on this inflammatory pain model in rat. The continuous infusion of endomorphin-1 caused dose-dependent antinociception, and the termination of endomorphin-1 delivery was followed by a gradual decrease in its effect. bPNP-3-8P in high doses decreased the inflammationinduced heat hyperalgesia, it did not potentiate the antinociceptive effect of endomorphin-1; instead, it even shortened the duration of its effect.

\subsection{Endomorphin-1}

The potent and selective activity of the endomorphins at the $\mu$-opioid receptor has led to the suggestion that this may 

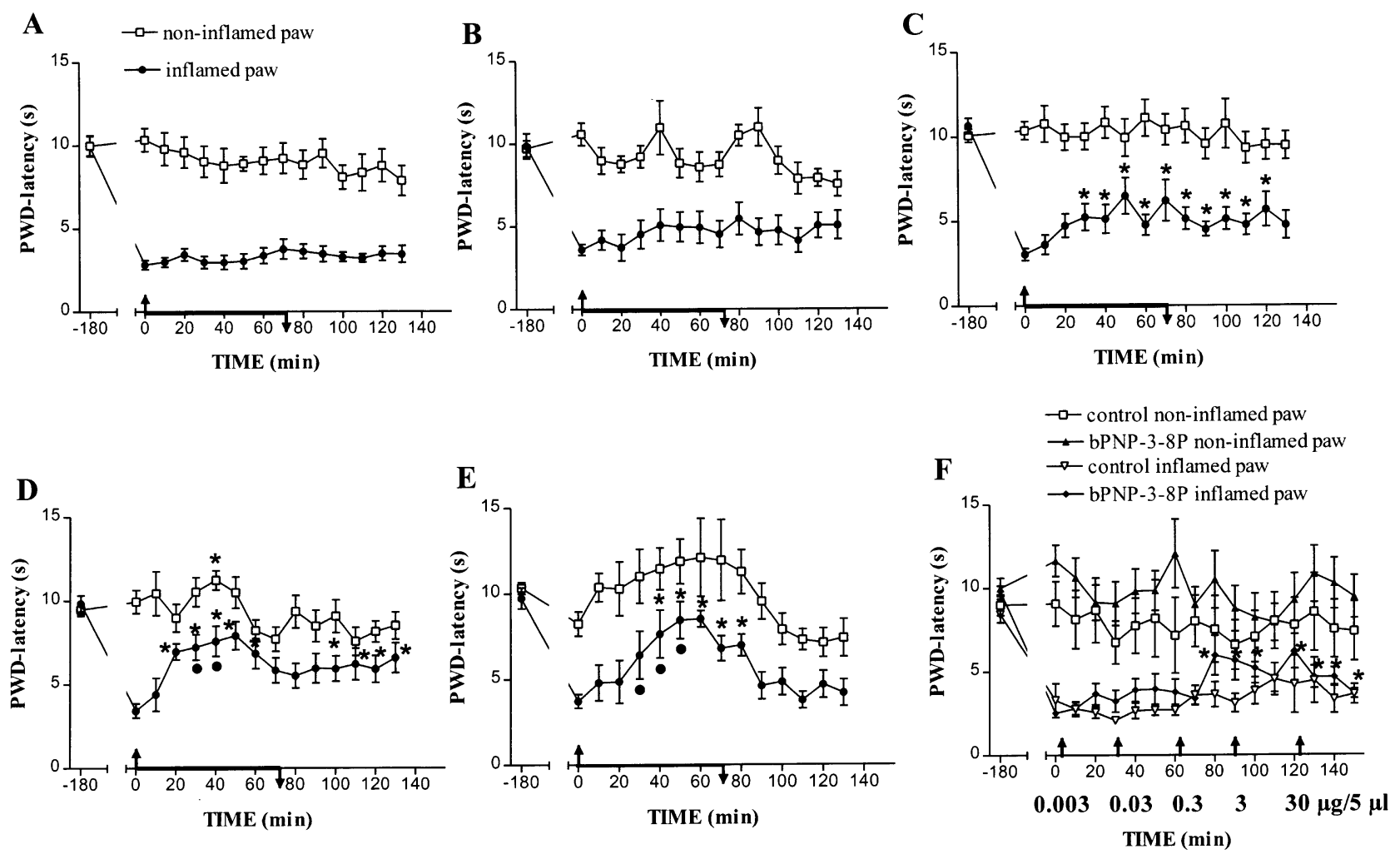

Fig. 1. Time course of the antinociceptive effects of different doses of endomorphin-1 ((B) 0.1 , (C) 0.3 , (D) 1 and (E) $2 \mu \mathrm{g} / \mathrm{min}$ ), bPNP-3-8P (F) and salinetreated control group (A). The horizontal line on the $x$-axis marks the period of drug administration, $\uparrow$ shows the initiation of the microinfusion and $\downarrow$ shows its termination. In the last figure (F) the arrows indicate the injection of the cumulatively administered bPNP-3-8P; the applied doses are written below the $x$-axis under each arrow. Each point represents the means \pm SEM of the result on five to 11 animals. The symbol $*$ indicates significant $(P<0.05)$ difference between the data point and the post-carrageenan baseline value. The symbol $\bullet$ indicates a non-significant difference between the data point and the pre-carrageenan baseline value.

lead to the development of new analgesics with less addictive properties than those of the traditional opioid receptor agonists. It has been reported that endomorphins exert an antinociceptive effect in different pain tests, although the potencies of the drugs largely depend on the species, on the applied pain tests and on the routes of administration (Zadina et al., 1997; Loh et al., 1998; Yamaguchi et al., 1998; Przewlocka et al., 1999; Sanchez-Blazquez et al., 1999a,b). Some differences from morphine have also been observed, i.e., Przewlocka et al. (1999) found that endomorphins displayed weaker analgesic effects than that of morphine on the formalin-induced pain response in both phases in rats after intrathecal administration. Thus, endomorphins appeared to be less potent than morphine in antagonizing inflammatory pain, but unlike morphine, they displayed strong analgesic activity against neuropathic pain. These effects of endomorphins contrast with the previous observations that the analgesic efficacy of opioids is increased in inflammation and reduced in neuropathic pain (Ossipov et al., 1999). It has been postulated that different $\mu$-opioid receptor subtypes may mediate the effects of morphine and endomorphins in neuropathic pain or that the molecular characteristics of the $\mu$-opioid receptors are modified by nerve injury (Przewlocki et al., 1999).
However, a recent study suggested that this may depend on the type of nerve injury, because the sensitivity to endomorphin-2 was reduced in rats exhibiting ongoing neuropathic pain-like behaviour after peripheral axotomy, and furthermore endomorphin-2 depressed the flexor reflex after carrageenan-induced inflammation (Grass et al., 2000). Our study demonstrated that continuous intrathecal administration of endomorphin-1 significantly decreased, but did not reverse, the inflammation-induced thermal hyperalgesia and it had no significant effect on the nociceptive threshold of the non-inflamed side at the doses used in this study.

There is some controversy concerning the data on the duration of action of endomorphins. Zadina et al. demonstrated that endomorphin-1 causes prolonged analgesia (mice, intracerebroventricular): about half of the animals were still analgesic $1 \mathrm{~h}$ after the administration of high doses $(10-20 \mu \mathrm{g})$. Essentially identical results were obtained by Przewlocka et al. (1999) in both thermal and mechanical pain tests in rats after intrathecal administration and by Wang et al. (1999) (intracerebroventricular or intrathecal) in the tail-flick test. In contrast, several studies revealed that the antinociception was short-lasting, i.e. it was completely absent $15-30$ min following intracerebro- 
A

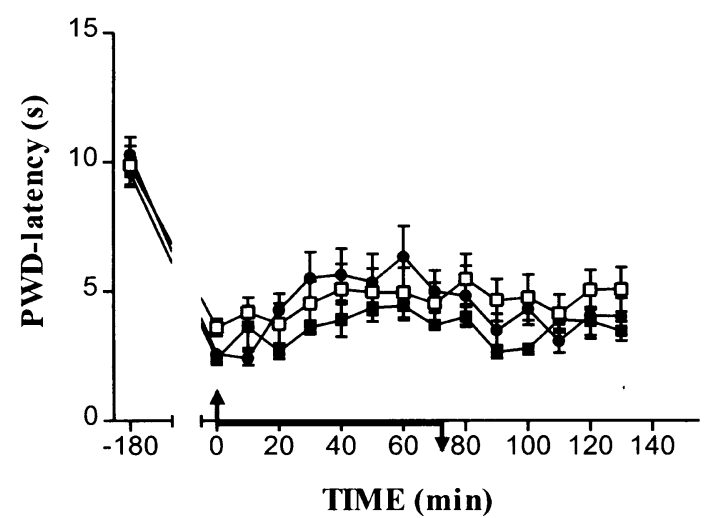

B

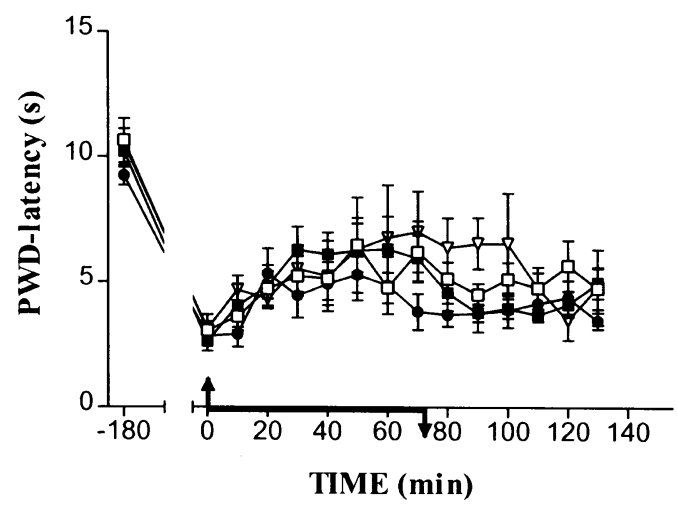

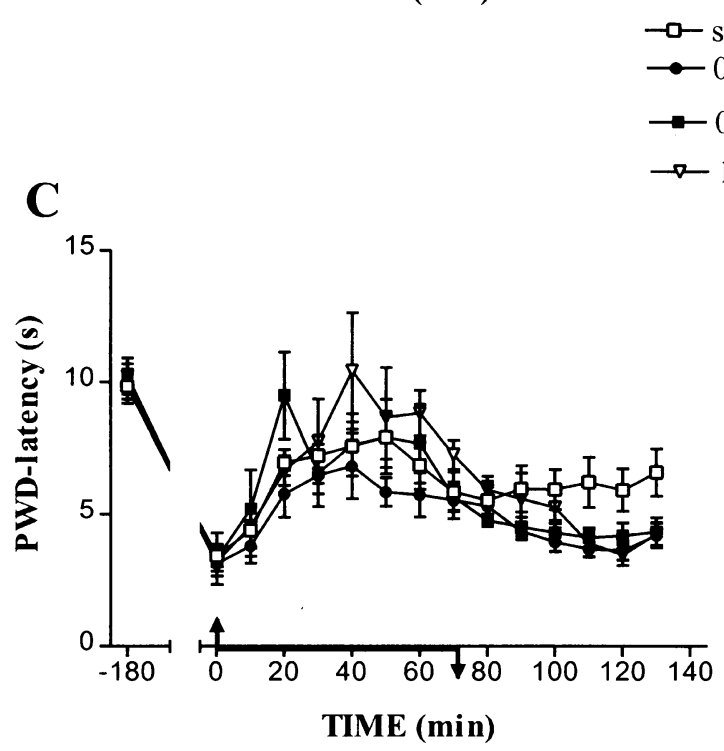

$\mathbf{E}$

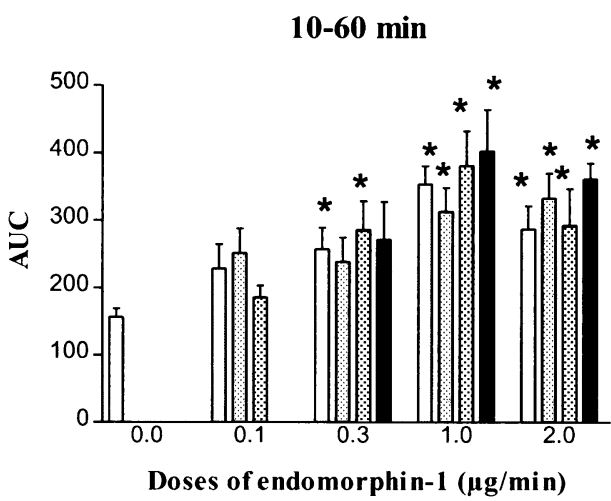

\section{$\mathbf{F}$}

$\square$ saline
D

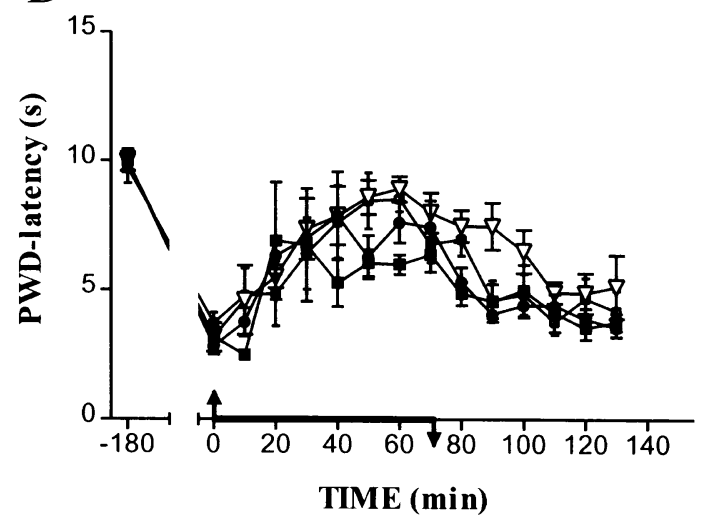

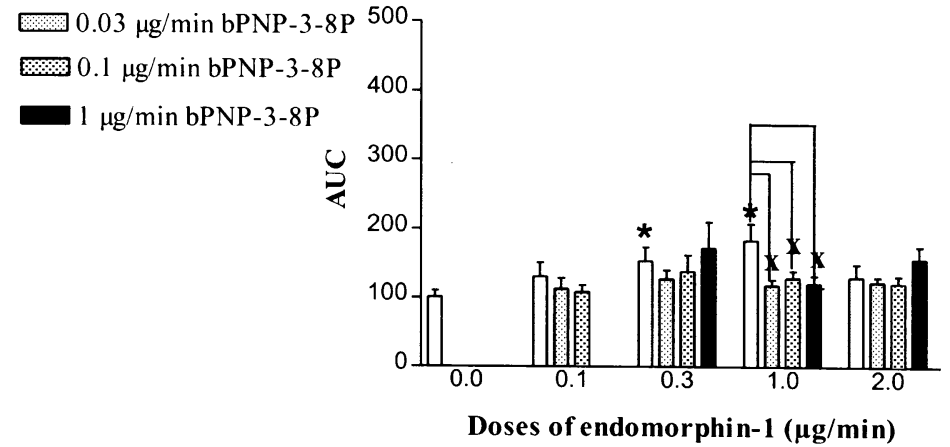

Fig. 2. Time course of the antinociceptive effect of different doses of endomorphin-1 ((A) 0.1, (B) 0.3, (C) 1 and (D) $2 \mu \mathrm{g} / \mathrm{min}$ ) in combination with bPNP-38P. The horizontal line on the $x$-axis marks the period of the drug administration, $\uparrow$ shows the initiation of the microinfusion and $\downarrow$ shows its termination. The magnitude of the dose-dependent effects of endomorphin-1 alone or with bPNP-3-8P during drug administration (10-60 min) (E) and after its termination $(100-130 \mathrm{~min})(\mathrm{F})$ are presented as AUC values. The symbol $*$ denotes a significant $(P<0.05)$ difference between the data point and the result for the control group (without any drug treatment). The symbol $\times$ and the connecting lines indicate significant differences between $1 \mu \mathrm{g} / \mathrm{min}$ endomorphin- 1 by itself and the combination treatment. Values represent the means \pm SEM of the data on five to 11 animals. 
ventricular or intrathecal injection (Stone et al., 1997; Horvath et al., 1999; Mizoguchi et al., 1999; Sakurada et al., 1999; Bhatia et al., 2000; Grass et al., 2000; Soignier et al., 2000). The short course of action suggests that the peptides may be broken down rapidly in the spinal cord. Endomorphins are small peptides, consisting of only four amino acids, which makes them vulnerable to rapid degradation by peptidases. The metabolic fate of endomorphins either in vitro or in the organism remains relatively unclear. It has been shown that dipeptidyl peptidase IV, a membranebound serine proteinase, plays a significant role in endomorphin-2 degradation, since endomorphin-2 was proved to be an excellent substrate for this enzyme in an in vitro assay, and a dipeptidyl peptidase IV inhibitor potentiates the analgesic actions of endomorphin-2 (Shane et al., 1999). In contrast, Rónai et al. (1999) found that another dipeptidyl aminopeptidase IV inhibitor - Diprotin A - neither potentiated nor prolonged the effect of endomorphin-1. A recent paper reported that the total in vitro degradation of endomorphin-1 requires more than $1 \mathrm{~h}$ (Péter et al., 1999); similarly, Sugimoto-Watanabe et al. (1999) found a slow degradation of endomorphin-1. These results support the notion that endomorphins are metabolized by the brain tissue, though the dynamics of the in vivo degradation remains unknown. Another possible explanation for the short-lasting effect of endomorphins could be that the $\mu$ opioid receptor is internalized from the membrane to the internal side of the cell by endocytosis after activation by the endomorphins (Burford et al., 1998; McConalogue et al., 1999). Our results do not support this possibility, because $\mu$ opioid receptors have been shown to be continuously antero- and retrogradely transported, which could indicate a continual turnover of the receptor, resulting in the efficacy of endomorphin-1 during the continuous administration ( $\mathrm{Ji}$ et al., 1995).

\subsection{Nocistatin/bPNP-3-8P}

Studies on nocistatin have indicated that it presumably acts as a neuromodulator in spinal pain processing. Although the nocistatin binding site has not been identified yet, it has been shown that it binds to the membrane of the mouse brain and spinal cord with high affinity (Okuda-Ashitaka et al., 1998). In pain transmission, nocistatin is reported to have different effects, including analgesia, no effect and nociception, depending on the animal species tested, applied doses, the route of administration and so on. Sakuda et al. observed that nocistatin blocks the thermal hyperalgesia and mechanical allodynia induced by nociceptin or prostaglandin- $E_{2}$ in mice after intrathecal administration (Okuda-Ashitaka et al., 1998). Nocistatin also attenuated the inflammatory mechanical hyperalgesia induced by carrageenan/kaolin (Nakagawa et al., 1999) and reversed the nociceptin-induced inhibition of morphine analgesia in rats after intracerebroventricular administration (Zhao et al., 1999), while it had no effect in acute heat pain tests (hot-plate, tail-flick) (Okuda-Ashitaka et al., 1998; Zhao et al., 1999; Yamamoto and Sakashita, 1999; Zeilhofer et al., 2000). There are some opposite results too, e.g. Xu et al. (1999) observed a facilitatory effect on the flexor reflex in anaesthetized decerebrated rats. While Yamamoto and Sakashita (1999) and Nakano et al. (2000) reported the antinociceptive effect of nocistatin in the formalin test, Zeilhofer et al. (2000) found that nocistatin dose-dependently increased the number of flinches during both phases of formalin-induced pain.

To date only a few data have been published on the cellular mechanisms of nocistatin. Zeilhofer et al. (2000) have shown that nocistatin reduces inhibitory glycinergic and GABAergic synaptic transmission in the spinal cord dorsal horn via a presynaptic mechanism involving Gi/oproteins, but leaves the excitatory glutamatergic transmission unaffected. The results suggest that nocistatin is released from such local interneurons onto the presynaptic terminals of inhibitory neurons. It is still not known under what physiological or pathophysiological conditions these peptides are released.

It has been shown that the C-terminal octapeptide of nocistatin, which is conserved in bovine, human and mouse species, appears to be the minimal essential core for biological affinity. It has been reported that the octapeptide bPNP-3-8P is as potent as the parent peptide in the inhibition of nociceptin-induced allodynia (Okuda-Ashitaka et al., 1998). However, Xu et al. (1999) did not find a significant effect of this octapeptide ( 7 and $70 \mathrm{ng}$ ), whereas we observed the significant effects of much higher doses of this octapeptide than those described by Okuda-Ashitaka et al. (1998). These discrepancies might be due to the differences between the species and/or the pain tests.

\subsection{Interaction}

Only a few interaction studies have been carried out on endomorphin with respect to antinociception. It has been observed that nociceptin potentiates or inhibits endomorphin-1-induced antinociception, depending on the route of administration: intracerebroventricular co-administration inhibits, while intrathecal co-administration synergizes the antinociceptive effects of endomorphin-1 (Wang et al., 1999a,b). Isobolographic analysis of the interaction between intrathecally administered endomorphin-1 and lidocaine revealed that concomitant administration of the two drugs produces synergistic suppression of the phase- 2 behavioural response in the rat formalin test (Hao et al., 1999). A recent article proposed potentiated antinociception after co-administration of the $\alpha 2$-adrenoceptor agonist clonidine and endomorphin-1 at the spinal level (Hao et al., 2000).

Both nocistatin-like and endomorphin-like immunoreactivities are present in the superficial laminae (I-II) of the dorsal horn (Martin-Schild et al., 1997; Okuda-Ashitaka et al., 1998; Wu et al., 1999). The similar patterns of their distribution in the spinal cord theoretically suggest some 
kind of interaction. Recent studies have shown that nocistatin (0.005-500 ng) does not affect morphine-induced analgesia after intrathecal administration, whereas it reversed the antagonistic effect of OFQ on morphine analgesia (doses of 0.05-500 ng) in a bell-shaped manner (Zhao et al., 1999). Furthermore, the classical opioid system did not participate in the analgesic action of nocistatin in the mouse formalin test at the spinal level, because naloxone did not influence the antinociceptive effect of nocistatin in the formalin test (Nakano et al., 2000). Our results are in agreement with these data, suggesting that there is no potentiating effect of the C-terminal octapeptide of nocistatin on endomorphin-1-induced antinociception in the rat thermal hyperalgesia model.

\subsection{Summary}

Administration of endogenous peptides might be accompanied by several advantages; since they are endogenous ligands, they have their own cleavage enzymes, and they have lower toxicity. The short-lasting effect of endomorphin- 1 and the low permeability of the blood-brain barrier for peptides suggest that the possible therapeutic role of endomorphins might lie in their continuous local administration peripherally or centrally. Our results suggest that this mode of application is a very effective method, since it dosedependently and significantly decreased the heat-hyperalgesia, and after cessation of the infusion the observed antinociceptive effect decreased. Thus, endomorphin-1 may be a novel and useful anti-hyperalgesic drug at the spinal level.

\section{Acknowledgements}

The authors thank Dr Renate Schwarz, Gödecke/Parke Davis Ltd, Vienna, Austria, for providing Ketalar. This work was supported by Hungarian Scientific Grant (OTKA T-029817) and Austrian Science and Research Liaison Office Grant.

\section{References}

Bhatia AR, Narita M, Mizoguchi H, Tseng LF. Spinal antinociceptive effects and G-protein activation induced by endomorphin-1 in the rat. Anesth Analg 2000;90:S302.

Burford NT, Tolbert LM, Sadee W. Specific G protein activation and $\mu$ opioid receptor internalization caused by morphine. DAMGO and endomorphin-1. Eur J Pharmacol 1998;342:123-126.

Connor M, Vaughan CW, Jennings EA, Allen RG, Christie MJ. Nociceptin, $\mathrm{Phe}^{1} \psi$-nociceptin ${ }_{1-13}$, nocistatin and prepronociceptin ${ }_{154-181}$ effects on calcium channel currents and a potasium current in rat locus coeruleus in vitro. Br J Pharmacol 1999;128:1779-1787.

Grass S, Wiesenfeld-Hallin Z, Xu X-J. The effect of intrathecal endomorphin-2 on the flexor reflex in normal, inflamed and axotomized rats: reduced effect in rats with autotomy. Neuroscience 2000;98:339-344.

Häbler H-J, Timmermann L, Stegmann J-U, Jänig W. Effects of nociceptin and nocistatin on antidromic vasodilatation in hairless skin of the rat hindlimb in vivo. Br J Pharmacol 1999;127:1719-1727.

Hao SL, Takahata O, Iwasaki H. Isobolographic analysis of interaction between spinal endomorphin-1, a newly isolated endogenous opioid peptide, and lidocaine in the rat formalin test. Neurosci Lett 1999;276:177-180.

Hao SL, Takahata O, Iwasaki H. Intrathecal endomorphin-1 produces antinociceptive activities modulated by alpha 2-adrenoceptors in the rat tail flick, tail pressure and formalin tests. Life Sci 2000;66:PL195-PL200.

Hargreaves K, Dubner R, Brown F, Flores C, Joris J. A new and sensitive method for measuring thermal nociception in cutaneous hyperalgesia. Pain 1988;32:77-88.

Hiramatsu M, Inoue K. Nociceptin/orphanin FQ and nocistatin on learning and memory impairment induced by scopolamine in mice. Br J Pharmacol 1999;127:655-660.

Horvath G. Endomorphin-1 and endomorphin-2. Pharmacology of the selective endogenous $\mu$-opioid receptor agonists. Pharmacol Ther 2000;89:437-463.

Horvath G, Szikszay M, Tomboly C, Benedek G. Antinociceptive effects of intrathecal endomorphin-1 and -2 in rats. Life Sci 1999;65:2635-2641.

Ji RR, Zhang Q, Law PY, Low HH, Elde R, Hokfelt T. Expression of mu-, delta-, and kappa-opioid receptor-like immunoreactivities in rat dorsal root ganglia after carrageenan-induced inflammation. J Neurosci $1995 ; 15: 8156-8166$

Loh HH, Liu H-C, Cavalli A, Yang W, Chen Y-F, Wei L-N. $\mu$ Opioid receptor knockout in mice: effects on ligand-induced analgesia and morphine lethality. Mol Brain Res 1998;54:321-326.

Martin-Schild S, Zadina JE, Gerall AA, Vigh S, Kastin AJ. Localization of endomorphin-2-like immunoreactivity in the rat medulla and spinal cord. Peptides 1997;18:1645-1649.

McConalogue K, Grady EF, Minnis J, Balestra B, Tonini M, Brecha NC, Bunnett NC, Sternini C. Activation and internalization of the $\mu$-opioid receptor by the newly discovered endogenous agonists, endomorphin-1 and endomorphin-2. Neuroscience 1999;90:1051-1059.

Mizoguchi H, Narita M, Oji DE, Suganuma C, Nagase H, Sora I, Uhl GR, Cheng EY, Tseng L-F. The $\mu$-opioid receptor gene - dose dependent reductions in G-protein activation in the pons/medulla and antinociception induced by endomorphins in $\mu$-opioid receptor knockout mice. Neuroscience 1999;94:203-207.

Nakagawa T, Kaneko M, Inamura S, Satoh M. Intracerebroventricular administration of nocistatin reduces inflammatory hyperalgesia in rats. Neurosci Lett 1999;265:64-66.

Nakano H, Minami T, Abe K, Arai T, Tokumura M, Ibii N, Okuda-Ashitaka $\mathrm{E}$, Mori H, Ito S. Effect of intrathecal nocistatin on the formalin-induced pain in mice versus that of nociceptin/orphanin FQ. J Pharmacol Exp Ther 2000;292:331-336.

Nicol B, Lambert DG, Rowbotham DJ, Okuda-Ashitaka E, Ito S, Smart D, McKnight AT. Nocistatin reverses nociceptin inhibition of glutamate release from rat brain slices. Eur J Pharmacol 1998;356:R1-R3.

Okuda-Ashitaka E, Ito S. Nocistatin: a novel neuropeptide encoded by the gene for the nociceptin/orphanin FQ precursor. Peptides 2000;21:11011109.

Okuda-Ashitaka E, Minami T, Tachibana S, Yoshihara Y, Nishiuchi Y, Kimura T, Ito S. Nocistatin, a peptide that blocks nociceptin action in pain transmission. Nature 1998;392:286-289.

Ossipov MH, Lopez Y, Nichols ML, Bian D, Porreca F. The loss of antinociceptive efficacy of spinal morphine in rats with nerve ligation injury is prevented by reducing spinal afferent drive. Neurosci Lett 1999;199:87-90.

Péter A, Tóth G, Tömböly Cs, Laus G, Tourwé D. Liquid chromatographic study of the enzymatic degradation of endomorphins, with identification by electrospray ionization mass spectrometry. J Chromatogr 1999;846:39-48.

Przewlocka B, Mika J, Labuz D, Toth G, Przewlocki R. Spinal analgesic action of endomorphins in acute, inflammatory and neuropathic pain in rats. Eur J Pharmacol 1999;367:189-196.

Przewlocki R, Labuz D, Mika J, Przewlocka B, Tomboly C, Toth G. Pain inhibition by endomorphins. Ann. N. Y. Acad. Sci. 1999;897:154-164.

Ren K, Williams GM, Hylden JLK, Ruda MA, Dubner R. The intrathecal administration of excitatory amino acid receptor antagonists selectively 
attenuated carrageenan-induced behavioral hyperalgesia in rats. Eur $\mathrm{J}$ Pharmacol 1992;219:235-243.

Rónai AZ, Timár J, Makó É, Erdô F, Gyarmati Zs, Tóth G, Orosz Gy, Fürst Zs, Székely JI. Diprotin A, an inhibitor of dipeptidyl aminopeptidase IV (EC 3.4.14.5) produces naloxone-reversible analgesia in rats. Life Sci 1999;64:145-152.

Sakurada S, Zadina JE, Kastin AJ, Katsuyama S, Fujimura T, Murayama K, Yuki M, Ueda H, Sakurada T. Differential involvement of $\mu$-opioid receptor subtypes in endomorphin-1- and -2-induced antinociception. Eur J Pharmacol 1999;372:25-30.

Sanchez-Blazquez P, DeAntoio I, Rodriguez-Diaz M, Garzón J. Antisense oligodeoxynucleotide targeting distinct exons of the cloned $\mu$-opioid receptor distinguish between endomorphin-1 and morphine supraspinal antinociception in mice. Antisense Nucleic Acid Drug Dev 1999a;9:253-260.

Sanchez-Blazquez P, Rodriguez-Diaz M, DeAntoio I, Garzón J. Endomorphin-1 and endomorphin-2 show differences in their activation of $\mu$ opioid receptor-regulated $\mathrm{G}$ proteins in supraspinal antinociception in mice. J Pharmacol Exp Ther 1999b;291:12-18.

Shane R, Wilk S, Bodnar RJ. Modulation of endomorphin-2-induced analgesia by dipeptidyl peptidase IV. Brain Res 1999;815:278-286.

Soignier RD, Vaccarino AL, Brennan AM, Kastin AJ, Zadina JE. Analgesic effects of endomorphin-1 and endomorphin- 2 in the formalin test in mice. Life Sci 2000;67:907-912.

Stone LS, Fairbanks CA, Laughlin TM, Nguyen HO, Bushy TM, Wessendorf MW, Wilcox GL. Spinal analgesic actions of the new endogenous opioid peptides endomorphin-1 and -2. NeuroReport 1997;8:3131-3135.

Sugimoto-Watanabe A, Kubota K, Fujibayashi K, Saito K. Antinociceptive effect and enzymatic degradation of endomorphin-1 in newborn rat spinal cord. Jpn J Pharmacol 1999;81:264-270.
Traub RJ. The spinal contribution of substance $\mathrm{P}$ to the generation and maintenance of inflammatory hyperalgesia in the rat. Pain 1996;67:151-161.

Wang J-L, Zhu C-B, Cao X-D, Wu G-C. Distinct effect of intracerebroventricular and intrathecal injections of nociceptin/orphanin FQ in the rat formalin test. Regul Pept 1999a;79:159-163.

Wang Y-Q, Zhu C-B, Wu G-C, Cao X-D, Wang Y, Cui DF. Effects of orphanin FQ on endomorphin-1 induced analgesia. Brain Res 1999b;835:241-246.

Wu SY, Dun SL, Wright MT, Chang J-K, Dun NJ. Endomorphin-like immunoreactivity in the rat dorsal horn and inhibition of substantia gelatinosa neurons in vitro. Neuroscience 1999;89:317-321.

Xu IS, Hashemi M, Caló G, Regoli D, Wiesenfeld-Hallin Z, Yacoub MH. Effects of intrathecal nocistatin on the flexor reflex and its interaction with orphanin FQ nociceptin. NeuroReport 1999;10:3681-3684.

Yamaguchi T, Kitagawa K, Kuraishi Y. Itch-associated response and antinociception induced by intracisternal endomorphins in mice. Jpn J Pharmacol 1998;78:337-343.

Yamamoto T, Sakashita Y. Effect of nocistatin and its interaction with nociceptin/orphanin FQ on the rat formalin test. Neurosci Lett 1999;262:179-182.

Zadina JE, Hackler L, Ge L-J, Kastin AJ. A potent and selective endogenous agonist for the $\mu$-opiate receptor. Nature 1997;386:499-502.

Zeilhofer HU, Muth-Selbach U, Gühring H, Erb K, Ahmadi S. Selective suppression of inhibitory synaptic transmission by nocistatin in the rat spinal cord dorsal horn. J Neurosci 2000;20:4922-4929.

Zhao C-S, Li B-S, Zhao G-Y, Liu H-X, Luo F, Wang Y, Tian J-H, Chang J$\mathrm{K}$, Han J-S. Nocistatin reverses the effect of orphanin FQ/nociceptin in antagonizing morphine analgesia. NeuroReport 1999;10:297-299. 